\title{
Concurrence of chromosome 6 chromothripsis and glioblastoma metastasis
}

\author{
Robert C. Rennert, MD, ${ }^{1}$ Reid R. Hoshide, MD, MPH, ${ }^{1}$ Jason W. Signorelli, BS, ${ }^{1}$ \\ Deirdre Amaro, MD, ${ }^{2}$ Jayson A. Sack, MD, ${ }^{1}$ Cameron W. Brennan, MD, ${ }^{3}$ and \\ Clark C. Chen, MD, PhD ${ }^{1}$
}

Departments of ${ }^{1}$ Neurosurgery and ${ }^{2}$ Pathology, University of California, San Diego, California; and ${ }^{3}$ Department of Neurosurgery, Memorial Sloan Kettering Cancer Center, New York, New York

\begin{abstract}
The authors report an unusual case of a widely metastatic glioblastoma. DNA copy number microarray profile of the resected specimen revealed complex rearrangements found throughout chromosome 6, a phenomenon known as chromothripsis. Such chromothripsis pattern was not observed in 50 nonmetastatic glioblastoma specimens analyzed. Analysis of the $1000+$ gliomas profiled by The Cancer Genome Atlas (TCGA) data set revealed one case of chromosome 6 chromothripsis resembling the case described here. This TCGA patient died within 6 months of undergoing tumor resection. Implications of these findings are reviewed in the context of the current literature.
\end{abstract}

https://thejns.org/doi/abs/10.3171/2016.4.JNS153052

KEY WORDS glioblastoma; metastasis; chromothripsis; oncology

$\mathrm{G}$ ENOMIC rearrangements are characterized by joining of segments of DNA that are discontinuous in the normal genome. Most solid tumor genomes can harbor tens to hundreds of these rearrangements scattered throughout the altered genome. ${ }^{14}$ Interestingly, recent advances in high-throughput genomics and informatics have revealed that in $2 \%-3 \%$ of solid tumors, hundreds of chromosomal rearrangements can be found clustered in one or a few chromosomal regions. ${ }^{23}$ The term chromothripsis has been coined to capture this phenomenon, because the clustering of rearrangements suggests that the region involved was "shattered" into little pieces at a point during tumor evolution and rejoined in a manner that failed to recapitulate the normal genome. , $^{8,36}$ Typically, these rearrangements lead to inactivation of genes or noncoding RNAs that are present in the involved region, though in rare instances the genomic rearrangement can result in gene activation or gain of novel functions. ${ }^{8,23}$ Cells that survive such a catastrophic event emerge with a highly rearranged genome that can confer selection advantages. ${ }^{20,23,24}$

Here we report the case of an unfortunate patient who suffered from a widely metastatic glioblastoma. DNA copy number microarray (OncoScan, Affymetrix) profile of the resected specimen revealed chromothripsis of chromosome 6. Such a chromothripsis pattern was not found in 50 nonmetastatic glioblastomas treated at the senior author's institution. One comparable case of chromosome 6 chromothripsis was seen in $1000+$ gliomas within The Cancer Genome Atlas (TCGA) data set, and the patient with this condition died within 6 months of undergoing tumor resection. Given previous reports demonstrating that the metastatic potential of cancer cells is suppressed by transfer of chromosome $6^{21,26,27,39}$ and enhanced by inactivation 

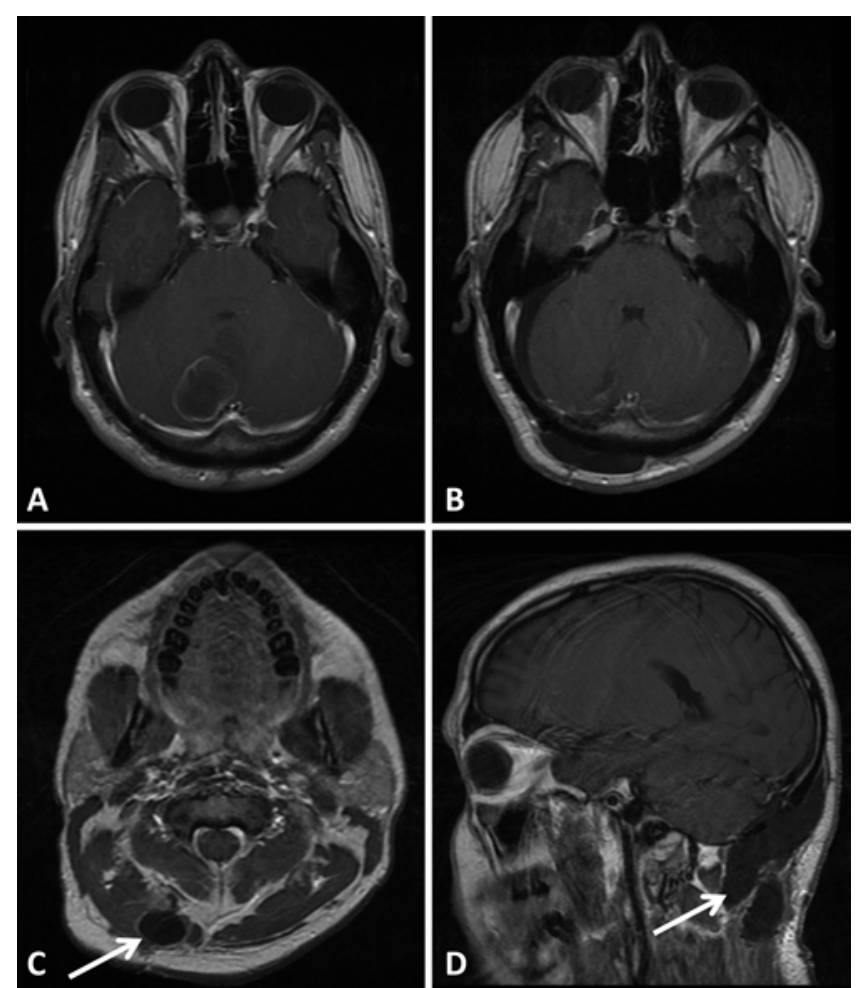

FIG. 1. Resection of cerebellar anaplastic oligoastrocytoma, with postoperative pseudomeningocele. Preoperative (A) and postoperative (B) T1-weighted contrast-enhanced axial MR images. Axial (C) and sagittal (D) T1-weighted contrast-enhanced MR images acquired 3 weeks after tumor resection demonstrating a cervical pseudomeningocele (arrows).

of key chromosome 6 genes, $2,6,11,29,34,40$ and given that chromothripsis often inactivates genes present in regions involved, we propose chromothripsis of chromosome 6 as a mechanism contributing to glioblastoma metastasis.

\section{Case Report}

This patient is a 23 -year-old man who underwent resection of a hemorrhagic cerebellar lesion 6 months prior to presentation (Fig. 1A and B). Postoperative findings were notable for a pseudomeningocele (Fig. 1C and D) that spontaneously resolved after a month. Pathological examination of this cerebellar lesion indicated an anaplastic oligoastrocytoma, and the patient was started on a course of temozolomide therapy. Surveillance imaging 6 months after the initial procedure revealed two extracranial, heterogeneously enhancing masses (Fig. 2A and B) located at the site of the previous pseudomeningocele. The lesions were resected and the pathology revealed glioblastoma (Fig. 2C-E and $\mathrm{G}$ ) with invasion of the surrounding musculature (Fig. 2E and F). Greater than $90 \%$ of the tumor cells from these specimens stained positive for $\mathrm{Ki}$ 67 (Fig. 2H). Isocitrate dehydrogenase 1 immunostaining was negative.

The patient was treated with involved-field irradiation, but he developed multifocal metastatic lesions including
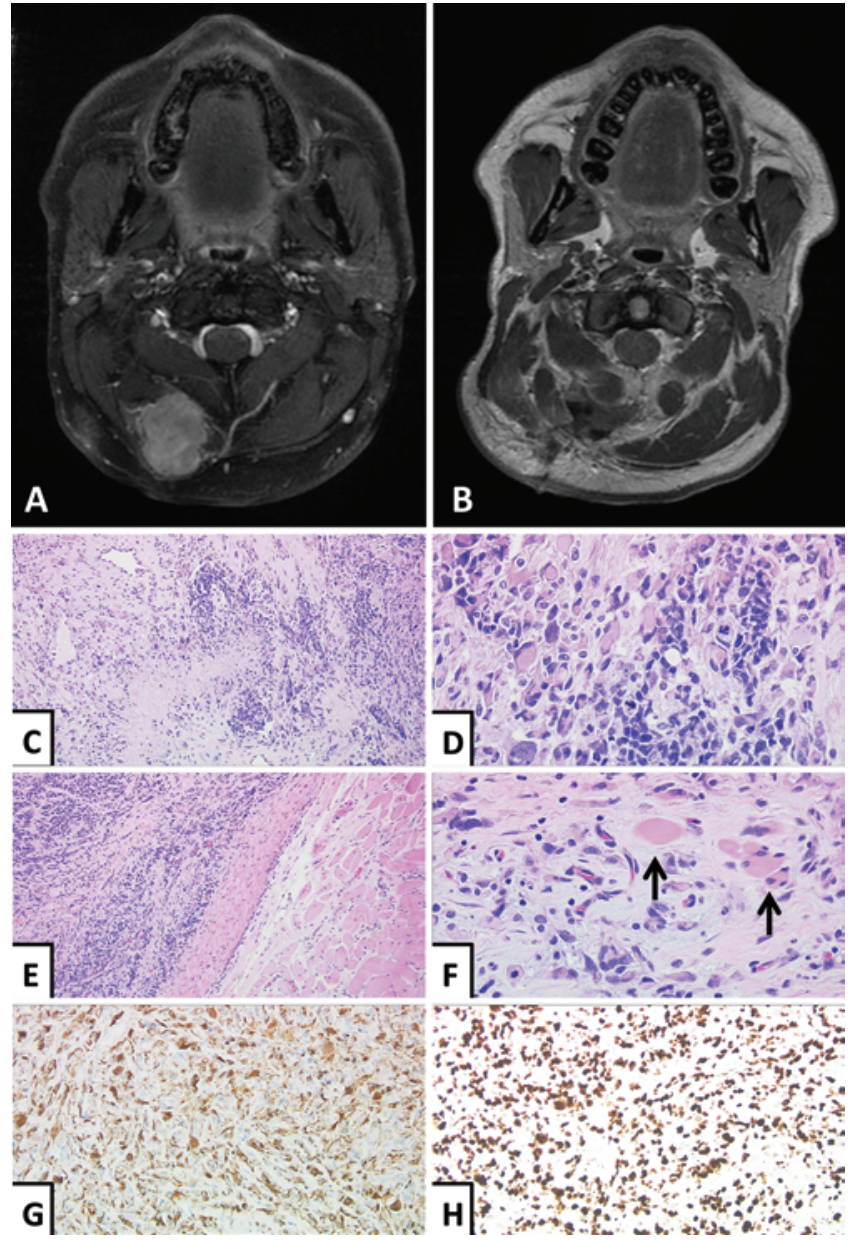

FIG. 2. Development, resection, and pathological analysis of cervical glioblastoma. A: Axial postcontrast MR images 6 months postresection demonstrating a new cervical mass in the area of the previous pseudomeningocele. B: Postoperative contrast-enhanced axial MR image of the cervical lesion. C: Necrosis with pseudopalisading is evident at lower power. $H \& E$, original magnification $\times 200$. D: Numerous mitotic figures, including atypical forms, are featured amid the striking astrocytic pleomorphism. $\mathrm{H} \& \mathrm{E}$, original magnification $\times 400$. E: The high-grade glial neoplasm involves adjacent soft tissue including skeletal muscle. $\mathrm{H} \& \mathrm{E}$, original magnification $\times 100$. F: Tumor cells flank individual skeletal muscle cells (arrows). $\mathrm{H} \& \mathrm{E}$, original magnification $\times 400$. G: Immunoreactivity confirms glial nature of tumor. GFAP, original magnification $\times 400$. $\mathrm{H}$ : Immunolabeling demonstrates high proliferative index. Ki 67 , original magnification $\times 400$. Figure is available in color online only.

additional lesions in the neck musculature (distant to the previous lesions) and multiple spinal (osseous and leptomeningeal) lesions (Fig. 3A-C). CT of the chest, abdomen, and pelvis revealed no metastatic involvement of other organs. Avastin therapy was initiated, and the patient died 2 months later.

The resected primary lesion was characterized by targeted sequencing of 47 cancer-pertinent genes (Supplemental Table 1) and by DNA (OncoScan) copy number microarray analysis. ${ }^{9}$ Targeted sequencing revealed a guanine-to-adenine transition at nucleotide 1633 of the phosphoinositol 3 kinase alpha subunit, resulting in a glu- 

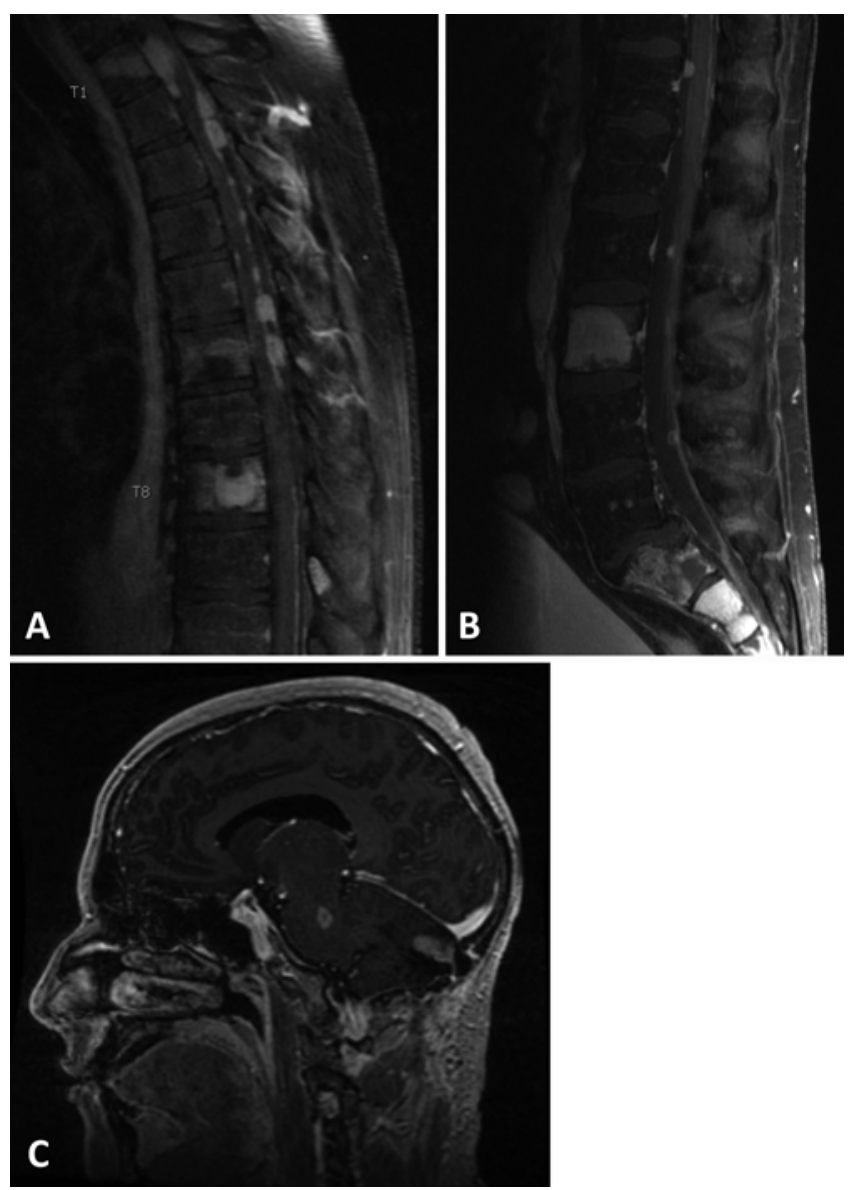

FIG. 3. Rapid development of multifocal neuroaxis metastases. Sagittal postcontrast thoracic $(\mathbf{A})$ and lumbar $(\mathbf{B})$ spine MR images obtained 2 months after resection of cervical glioblastoma, demonstrating multiple, new osseous and leptomeningeal lesions. Sagittal postcontrast brain MR image (C) obtained at the same time demonstrating a new right pontine lesion, with multiple supratentorial leptomeningeal lesions and a right cerebellar recurrence also found. Multiple cervical spine leptomeningeal and lumbar nerve root lesions were also seen on MRI (not shown).

tamic acid to lysine substitution at amino acid position 545 (PIK3CA c.1633G>A (p.E545 K)). This amino acid position, which localizes to the helical domain, is a known mutational hotspot within PIK3CA. This is the most frequently observed PIK3CA mutation in multiple cancer types and has been shown to result in increased kinase activity and induce tumor formation in multiple experimental systems. ${ }^{13,19,38}$

The OncoScan profile revealed deletions at 1q, 10q (encompassing the PTEN locus), 12q, 13q, 14q, 15q, 16p, 16q, 17p (encompassing TP53), 18q, and 21q, and chromothripsis of chromosome 6 (Fig. 4). We compared the OncoScan results of this metastatic glioblastoma to those derived from 50 consecutive nonmetastatic glioblastomas treated at the same institution and found chromothripsis of chromosome 6 to be the only genomic feature unique to this metastatic glioblastoma. Analysis of the 1000+ lowgrade gliomas and glioblastomas in the TCGA data set revealed only one case of chromosome 6 chromothripsis of comparable severity (Fig. 5). This TCGA patient died within 6 months of resection.

\section{Discussion}

While the interpretation of " $\mathrm{N}$ of 1 " studies warrants extreme caution, thoughtful consideration of these studies has yielded insights that that have led to significant scientific advances. ${ }^{22}$ It is in this context that we present our finding of chromosome 6 chromothripsis in a metastatic glioblastoma specimen. Despite the aggressively infiltrative nature of high-grade glial tumors, secondary metastasis to non-CNS sites is exceedingly rare, especially to the skin and soft tissue. In our literature search, we have identified a total of 19 such cases s, $^{1,4,5,7,10,12,15,17,18,25,28,30-33,37}$ (Table 1). Given the rarity of the phenomenon, it is of no surprise that its etiology remains poorly understood. While seeding secondary to surgical manipulation has been suggested as a potential mechanism, ${ }^{35}$ and this process may explain the tumor recurrence at the site of the postoperative pseudomeningocele in our patient, we cannot exclude the possibility of microscopic systemic metastasis because of the subsequent development of distant soft-tissue and multifocal osseous lesions. In fact, rare cases of glioblastoma metastasis in the absence of surgical manipulation ${ }^{3,16}$ suggest that the inherent genomic landscape of the cancer may be contributory to its metastatic potential.

Consistent with this hypothesis, genomic analysis of the metastatic glioblastoma specimen revealed a highly unusual genomic rearrangement pattern that was not observed in 50 consecutive nonmetastatic glioblastomas treated at the same institution-the chromothripsis of chromosome 6. TCGA analysis confirmed the rarity of chromosome 6 chromothripsis in clinical glioblastoma specimens. While there are no clinical annotations of glioblastoma metastasis for this TCGA patient, the poor clinical course (6-month overall survival after resection) is consistent with an aggressively infiltrative tumor.

These findings are particularly intriguing in the context of a substantiated body of literature that microcellmediated transfer of chromosome 6 into human cancer cell lines suppresses metastatic potential. . $126,27,39$ Moreover, inactivation or loss of key genes present on chromosome 6 greatly facilitates the metastatic potential of cancer cells. . $^{2,11,29,34,40}$ Since chromothripsis most commonly results in inactivation of genes or noncoding RNAs present in the involved region, our findings suggest that chromothripsis of chromosome 6 may inactivate key metastasis suppressor genes and facilitate glioblastoma metastasis. While the proposed hypothesis is intriguing, it is conceivable that other mutational events, including those not characterized by our gene panel or DNA copy number microarray, play contributory roles to glioblastoma metastasis. As such, clinical and experimental validations of the findings presented in this case report are warranted.

\section{Conclusions}

Chromothripsis of chromosome 6 may facilitate the metastatic potential of glioblastoma cells. 


A chr1 chr2 chr3 chr4 chr5 chr6 chr7 chr8 chro chr10 chr11 chr12
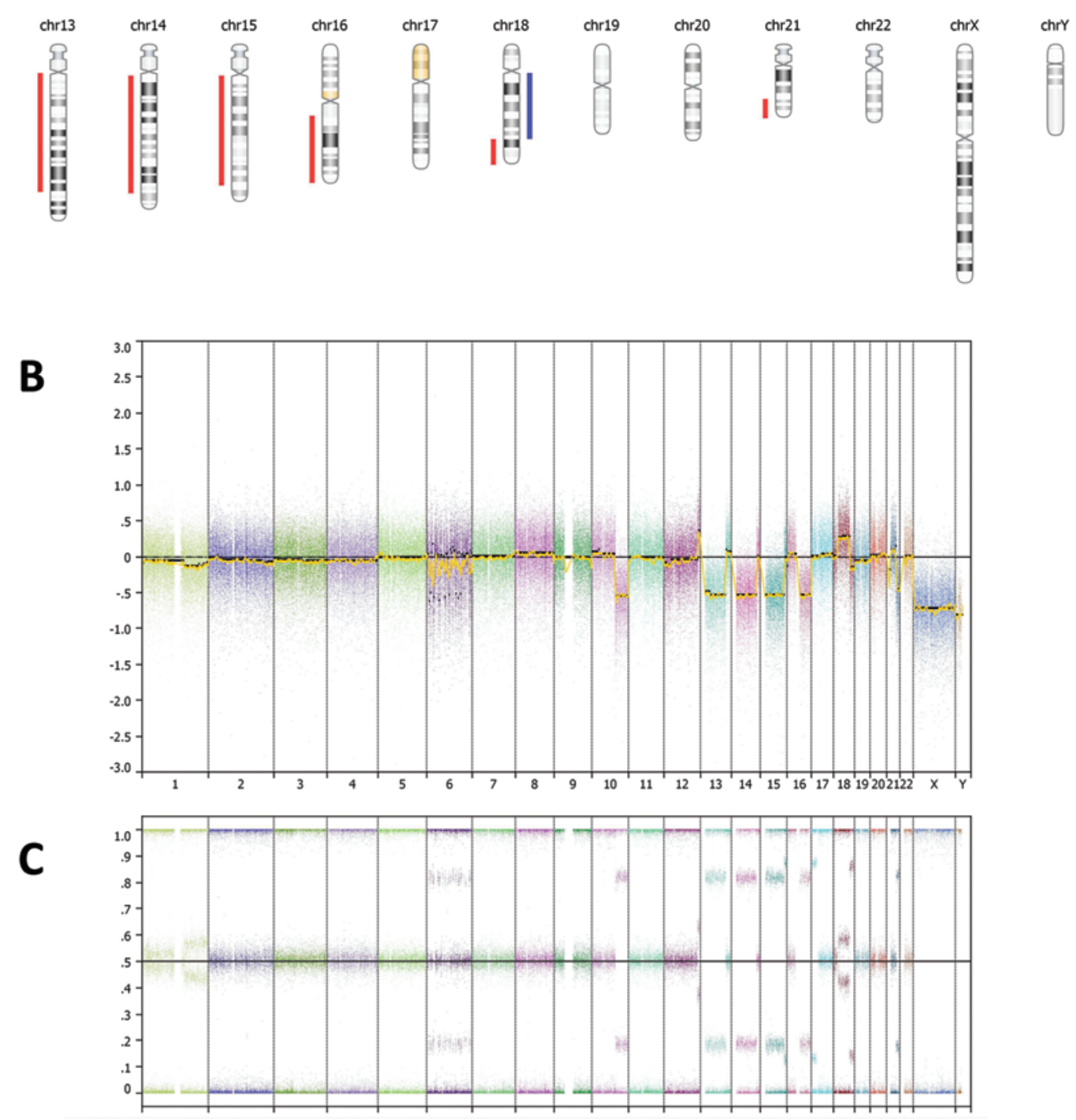

FIG. 4. OncoScan chromosomal analysis results. Karyotype (A), log-ratio (B), and B-allele (C) frequency plots demonstrate chromosome 6 chromothripsis. Multiple copy number abnormalities and several large regions of loss of heterozygosity (LOH) were also found, including loss of 1q, deletion of distal 10q including the PTEN locus, and 17p LOH including the TP53 locus. Also noted were deletions of 13q, 14q, 15q, and 16q; copy gains were noted at distal 12q and proximal 18q. No high copy gains or regions of amplification were identified. $\mathrm{chr}=$ chromosome. Figure is available in color online only. 
TCGA-12-1089-01A-01D-0517-01

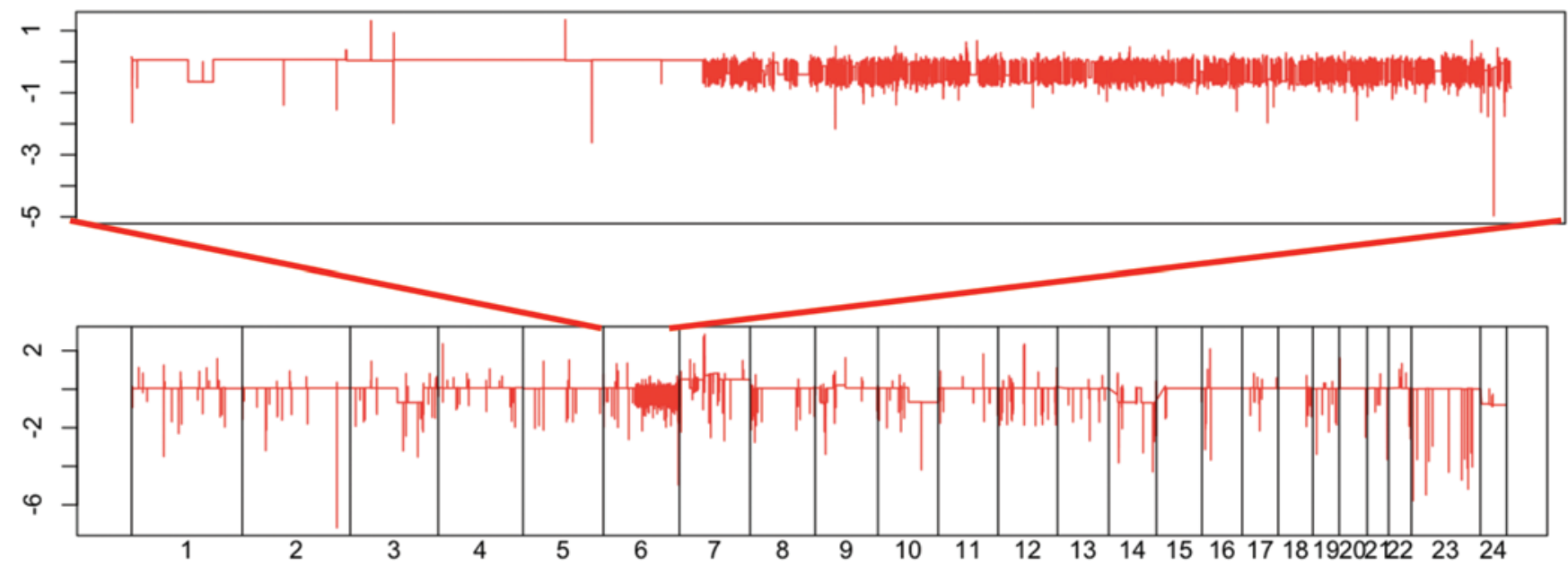

FIG. 5. TCGA analysis for chromosome 6 chromothripsis. The number of copy number aberration (CNA) breaks was examined for the 1000+ low-grade gliomas and glioblastomas in the TCGA data set. Each chromosome was normalized by the total number of CNA breaks in all other chromosomes. One single case of chromosome 6 chromothripsis of comparable severity to the presented case was identified (lower). Break count for chromosome 6 in this case was magnified (upper). Figure is available in color online only.

TABLE 1. Summary of cases of glioblastoma metastasis to the skin

\begin{tabular}{|c|c|c|c|c|}
\hline Authors \& Year & Age (yrs), Sex & Primary Histopathology (WHO grade) & Site of Primary Malignancy & Location of Metastasis \\
\hline Carvalho et al., 1991 & $26, F$ & Primary GBM (IV) & Rt temporal lobe & Scalp \& cervical lymph node \\
\hline \multirow[t]{2}{*}{ Vural et al., 1996} & $40, M$ & Primary GBM (IV) & Rt temporoparietal & Cervical subcutaneous tissue \\
\hline & $49, \mathrm{M}$ & Primary GBM (IV) & Lt cerebral hemisphere & Scalp \\
\hline Houston et al., 2000 & $32, \mathrm{M}$ & Primary GBM (IV) & Lt temporal lobe & Scalp \\
\hline Figueroa et al., 2002 & $35, M$ & Primary GBM (IV) & Lt temporal lobe & Scalp \\
\hline Santos et al., 2003 & $42, \mathrm{M}$ & Primary GBM (IV) & Lt frontoparietal & Scalp \\
\hline Allan, 2004 & $60, M$ & Primary GBM (IV) & Unknown & Scalp \\
\hline Bouillot-Eimer et al., 2005 & $60, \mathrm{M}$ & Primary GBM (IV) & Lt parietal lobe & Scalp \\
\hline Jain et al., 2005 & $49, \mathrm{M}$ & Primary GBM (IV) & Rt temporoparietal & Scalp \\
\hline Schultz et al., 2005 & $74, \mathrm{~F}$ & Primary GBM (IV) & Lt temporal lobe & Scalp \\
\hline Saad et al., 2007 & $13, M$ & Primary GBM (IV) & Lt frontal lobe & Scalp \& temporal bone \\
\hline \multirow[t]{2}{*}{ Mentrikoski et al., 2008} & $58, \mathrm{~F}$ & Primary GBM (IV) & Lt frontal lobe & Scalp \\
\hline & $41, \mathrm{M}$ & Anaplastic oligodendroglioma (III) & Unknown & Scalp \\
\hline Miliaras et al., 2009 & $63, \mathrm{M}$ & Primary GBM (IV) & Lt frontoparietal & Scapular subcutaneous tissue \\
\hline \multirow[t]{2}{*}{ Senetta et al., 2009} & $48, F$ & Primary GBM (IV) & Rt frontoparietal & Scalp \\
\hline & $53, \mathrm{~F}$ & Primary GBM (IV) & Lt frontal lobe & Scalp \\
\hline Jusué Torres et al., 2011 & $63, \mathrm{~F}$ & Primary GBM (IV) & Rt frontal lobe & Scalp \\
\hline Guo et al., 2012 & $19, \mathrm{~F}$ & Primary GBM (IV) & Pons & Cervical subcutaneous tissue \\
\hline Ginat et al., 2013 & $62, \mathrm{M}$ & Primary GBM (IV) & Lt frontal lobe & Scalp \\
\hline Present case & $23, \mathrm{M}$ & Anaplastic oligoastrocytoma (III) & Rt cerebellar hemisphere & Cervical subcutaneous tissue \\
\hline
\end{tabular}

$\mathrm{GBM}=$ glioblastoma . 


\section{References}

1. Allan RS: Scalp metastasis from glioblastoma. J Neurol Neurosurg Psychiatry 75:559, 2004

2. Alvarez M, Strasberg Rieber M, Rieber M: Chromosome6-mediated suppression of metastatic ability increases basal expression of UV-inducible superoxide dismutase and induction of p53. Int J Cancer 77:586-591, 1998

3. Anzil AP: Glioblastoma multiforme with extracranial metastases in the absence of previous craniotomy. Case report. J Neurosurg 33:88-94, 1970

4. Bouillot-Eimer S, Loiseau H, Vital A: Subcutaneous tumoral seeding from a glioblastoma following stereotactic biopsy: case report and review of the literature. Clin Neuropathol 24:247-251, 2005

5. Carvalho PA, Schwartz RB, Alexander E III, Loeffler JS, Zimmerman RE, Nagel JS, et al: Extracranial metastatic glioblastoma: appearance on thallium-201-chloride/ technetium-99m-HMPAO SPECT images. J Nucl Med 32:322-324, 1991

6. Fidler IJ, Radinsky R: Search for genes that suppress cancer metastasis. J Natl Cancer Inst 88:1700-1703, 1996

7. Figueroa P, Lupton JR, Remington T, Olding M, Jones RV, Sekhar LN, et al: Cutaneous metastasis from an intracranial glioblastoma multiforme. J Am Acad Dermatol 46:297300, 2002

8. Forment JV, Kaidi A, Jackson SP: Chromothripsis and cancer: causes and consequences of chromosome shattering. Nat Rev Cancer 12:663-670, 2012

9. Foster JM, Oumie A, Togneri FS, Vasques FR, Hau D, Taylor $\mathrm{M}$, et al: Cross-laboratory validation of the OncoScan ${ }^{\circledR}$ FFPE Assay, a multiplex tool for whole genome tumour profiling. BMC Med Genomics 8:5, 2015

10. Ginat DT, Kelly HR, Schaefer PW, Davidson CJ, Curry W: Recurrent scalp metastasis from glioblastoma following resection. Clin Neurol Neurosurg 115:461-463, 2013

11. Goldberg SF, Miele ME, Hatta N, Takata M, Paquette-Straub C, Freedman LP, et al: Melanoma metastasis suppression by chromosome 6: evidence for a pathway regulated by CRSP3 and TXNIP. Cancer Res 63:432-440, 2003

12. Guo L, Qiu Y, Ge J, Zhou D: Glioblastoma multiforme with subcutaneous metastases, case report and literature review. J Korean Neurosurg Soc 52:484-487, 2012

13. Gustin JP, Karakas B, Weiss MB, Abukhdeir AM, Lauring J, Garay JP, et al: Knockin of mutant PIK3CA activates multiple oncogenic pathways. Proc Natl Acad Sci U S A 106:2835-2840, 2009

14. Hasty P, Montagna C: Chromosomal rearrangements in cancer: detection and potential causal mechanisms. Mol Cell Oncol 1:e29904, 2014

15. Houston SC, Crocker IR, Brat DJ, Olson JJ: Extraneural metastatic glioblastoma after interstitial brachytherapy. Int J Radiat Oncol Biol Phys 48:831-836, 2000

16. Hulbanni S, Goodman PA: Glioblastoma multiforme with extraneural metastases in the absence of previous surgery. Cancer 37:1577-1583, 1976

17. Jain N, Mirakhur M, Flynn P, Choudhari KA: Cutaneous metastasis from glioblastoma. Br J Neurosurg 19:65-68, 2005

18. Jusué Torres I, Jerez Fernandez P, Ortega Zufiria J, Rodriguez Barbero JM: Skin spread from an intracranial glioblastoma: case report and review of the literature. BMJ Case Rep 2011:bcr0920114858, 2011

19. Karakas B, Bachman KE, Park BH: Mutation of the PIK3CA oncogene in human cancers. Br J Cancer 94:455-459, 2006

20. Kloosterman WP, Hoogstraat M, Paling O, TavakoliYaraki M, Renkens I, Vermaat JS, et al: Chromothripsis is a common mechanism driving genomic rearrangements in primary and metastatic colorectal cancer. Genome Biol 12:R103, 2011
21. Lee JH, Welch DR: Identification of highly expressed genes in metastasis-suppressed chromosome 6/human malignant melanoma hybrid cells using subtractive hybridization and differential display. Int J Cancer 71:1035-1044, 1997

22. Lillie EO, Patay B, Diamant J, Issell B, Topol EJ, Schork NJ: The n-of-1 clinical trial: the ultimate strategy for individualizing medicine? Per Med 8:161-173, 2011

23. Maher CA, Wilson RK: Chromothripsis and human disease: piecing together the shattering process. Cell 148:29-32, 2012

24. Malhotra A, Lindberg M, Faust GG, Leibowitz ML, Clark RA, Layer RM, et al: Breakpoint profiling of 64 cancer genomes reveals numerous complex rearrangements spawned by homology-independent mechanisms. Genome Res 23:762-776, 2013

25. Mentrikoski M, Johnson MD, Korones DN, Scott GA: Glioblastoma multiforme in skin: a report of 2 cases and review of the literature. Am J Dermatopathol 30:381-384, 2008

26. Miele ME, Jewett MD, Goldberg SF, Hyatt DL, Morelli C, Gualandi F, et al: A human melanoma metastasis-suppressor locus maps to 6q16.3-q23. Int J Cancer 86:524-528, 2000

27. Miele ME, Robertson G, Lee JH, Coleman A, McGary CT, Fisher PB, et al: Metastasis suppressed, but tumorigenicity and local invasiveness unaffected, in the human melanoma cell line MelJuSo after introduction of human chromosomes 1 or 6. Mol Carcinog 15:284-299, 1996

28. Miliaras G, Tsitsopoulos PP, Markoula S, Kyritsis A, Polyzoidis KS, Malamou-Mitsi V: Multifocal glioblastoma with remote cutaneous metastasis: a case report and review of the literature. Cent Eur Neurosurg 70:39-42, 2009

29. Muir AI, Chamberlain L, Elshourbagy NA, Michalovich D, Moore DJ, Calamari A, et al: AXOR12, a novel human G protein-coupled receptor, activated by the peptide KiSS-1. J Biol Chem 276:28969-28975, 2001

30. Saad AG, Sachs J, Turner CD, Proctor M, Marcus KJ, Wang L, et al: Extracranial metastases of glioblastoma in a child: case report and review of the literature. J Pediatr Hematol Oncol 29:190-194, 2007

31. Santos AV, Saraiva PF, Santiago B: [Extracranial metastasis of glioblastoma multiforme.] Acta Med Port 16:209-211, 2003 (Portuguese)

32. Schultz S, Pinsky GS, Wu NC, Chamberlain MC, Rodrigo AS, Martin SE: Fine needle aspiration diagnosis of extracranial glioblastoma multiforme: Case report and review of the literature. Cytojournal 2:19, 2005

33. Senetta R, Trevisan E, Rudà R, Benech F, Soffietti R, Cassoni P: Skin metastases of glioblastoma in the absence of intracranial progression are associated with a shift towards a mesenchymal immunophenotype: report of two cases. Acta Neuropathol 118:313-316, 2009

34. Srikantan V, Sesterhenn IA, Davis L, Hankins GR, Avallone FA, Livezey JR, et al: Allelic loss on chromosome 6q in primary prostate cancer. Int J Cancer 84:331-335, 1999

35. Steinmetz MP, Barnett GH, Kim BS, Chidel MA, Suh JH: Metastatic seeding of the stereotactic biopsy tract in glioblastoma multiforme: case report and review of the literature. J Neurooncol 55:167-171, 2001

36. Stephens PJ, Greenman CD, Fu B, Yang F, Bignell GR, Mudie LJ, et al: Massive genomic rearrangement acquired in a single catastrophic event during cancer development. Cell 144:27-40, 2011

37. Vural G, Hagmar B, Walaas L: Extracranial metastasis of glioblastoma multiforme diagnosed by fine-needle aspiration: a report of two cases and a review of the literature. Diagn Cytopathol 15:60-65, 1996

38. Wang GM, Wong HY, Konishi H, Blair BG, Abukhdeir AM, Gustin JP, et al: Single copies of mutant KRAS and mutant PIK3CA cooperate in immortalized human epithelial cells to induce tumor formation. Cancer Res 73:3248-3261, 2013 
39. Welch DR, Chen P, Miele ME, McGary CT, Bower JM, Stanbridge EJ, et al: Microcell-mediated transfer of chromosome 6 into metastatic human C8161 melanoma cells suppresses metastasis but does not inhibit tumorigenicity. Oncogene 9:255-262, 1994

40. West A, Vojta PJ, Welch DR, Weissman BE: Chromosome localization and genomic structure of the KiSS-1 metastasis suppressor gene (KISS1). Genomics 54:145-148, 1998

\section{Disclosures}

The authors report no conflict of interest concerning the materials or methods used in this study or the findings specified in this paper.

\section{Author Contributions}

Conception and design: Chen, Rennert, Hoshide, Signorelli, Sack.
Acquisition of data: all authors. Analysis and interpretation of data: all authors. Drafting the article: Chen, Rennert, Hoshide, Signorelli, Sack. Critically revising the article: all authors.

Reviewed submitted version of manuscript: all authors. Approved the final version of the manuscript on behalf of all authors: Chen.

\section{Supplemental Information}

Online-Only Content

Supplemental material is available with the online version of the article.

Supplemental Table 1. https://thejns.org/doi/suppl/10.3171/ 2016.4.JNS153052.

\section{Correspondence}

Clark C. Chen, Department of Neurosurgery, University of California, San Diego, 200 West Arbor Dr., San Diego, CA 92103. email: clarkchen@ucsd.edu. 